\title{
Prospección serológica del virus parainfluenza 3 en camélidos sudamericanos en Chile
}

\author{
A serological survey of parainfluenza-3 virus in South American camelids from Chile \\ CP Cepeda, C Navarro, MO Celedón* \\ Departamento de Medicina Preventiva Animal, Facultad de Ciencias Veterinarias y Pecuarias, \\ Universidad de Chile, Santiago, Chile.
}

\begin{abstract}
SUMMARY
A total of 370 sera collected from 87 alpacas (Lama pacos), 88 llamas (Lama glama), 89 guanacos (Lama guanicoe) and 106 vicunas (Vicugna vicugna) were investigated for the presence of antibodies to parainfluenza 3 virus (PIV-3). Hemagglutination inhibition test indicated that a total of 91 (24.6\%) South American camelids (SAC) had PIV-3 antibodies, including 18 (20.7\%) alpacas, 36 (40.9\%) llamas, 27 (18.9\%) vicunas and 10 (11.2\%) guanacos. Titers of the positive samples ranged from 8 to 256 with a geometric mean of 31 . These results establish that SAC in Chile are infected with PIV-3.
\end{abstract}

Palabras clave: serología, camélidos sudamericanos, virus parainfluenza 3.

Key words: serology, South American camelids, parainfluenza virus 3.

\section{INTRODUCCIÓN}

Los camélidos en Sudamérica están representados por cuatro especies, dos domésticas: la alpaca (Lama pacos) y la llama (Lama glama) y dos silvestres: el guanaco (Lama guanicoe) y la vicuña (Vicugna vicugna). La población de camélidos sudamericanos (CSA) estimada en Chile es de 179.589 animales, ubicándose el mayor número de animales domésticos en el altiplano de la Región de Arica y Parinacota y Región de Tarapacá. En cuanto a los camélidos silvestres, casi la totalidad de las vicuñas se encuentra en las dos regiones antes mencionadas, y la mayor concentración de guanacos se sitúa en la Región de Magallanes y la Antártica Chilena. A pesar de que los camélidos domésticos representan sólo el $1 \%$ de la producción pecuaria nacional, su mayor importancia radica en que son el sustento para pueblos originarios que viven en condiciones geográficas extremas, como el altiplano chileno (FIA 2000).

Mediante prospecciones serológicas en CSA ubicados en diferentes zonas geográficas de Chile, se ha detectado seropositividad para el virus herpes equino 1 (Vergara 2004) y para el virus de la diarrea viral bovina (Celedón y col 2001), a la vez que se ha aislado el virus diarrea viral bovina desde animales sanos y enfermos (Celedón y col 2006). Hasta ahora se desconoce si los CSA de Chile están infectados con el virus parainfluenza-3 (VPI-3).

El VPI-3 pertenece al género Respirovirus de la familia Paramyxoviridae y es responsable de producir

Aceptado: 06.10.2010.

* Casilla 2 correo 15, Santiago, Chile; oceledon@uchile.cl enfermedad respiratoria en animales rumiantes domésticos y silvestres (Murphy y col 1999). En Chile, el virus fue aislado desde un bovino con enfermedad respiratoria (Berríos y col 1985) y desde el pulmón de un cordero con lesiones neumónicas (Berríos y col 1991). Mediante prospecciones serológicas y estudios de prevalencia serológica se han detectado anticuerpos en bovinos de la Provincia de Valdivia (Reinhardt y col 1980), en bovinos de la zona central-sur (Berríos y col 1983), en ovinos de las Regiones de Valparaíso y del Libertador General Bernardo O'Higgins (Berríos y col 1987) y en ovinos de la Región de Los Lagos (Riedemann y col 1991). En este trabajo se plantea como objetivo conocer si los CSA de Chile se han infectado con VPI-3 a través de la detección de anticuerpos inhibidores de la hemoaglutinación en muestras de suero.

\section{MATERIAL Y MÉTODOS}

\section{MUESTRAS}

Para conocer si los CSA se han infectado con el VPI-3 se utilizó un total de 370 muestras de sueros procedentes de 87 alpacas, 88 llamas, 89 guanacos y 106 vicuñas. Las muestras de sangre fueron obtenidas entre los años 2000 y 2006 por punción de la vena yugular de animales adultos clínicamente sanos mediante un muestreo no aleatorio. Las muestras de alpacas procedían de cuatro rebaños ubicados en la Región Metropolitana; las de llamas, de cuatro rebaños de la Región Metropolitana y de 10 rebaños de la Región de Arica y Parinacota; las muestras de guanacos se obtuvieron de animales capturados y mantenidos en cautiverio procedentes de 
un rebaño de la Región Metropolitana y de un rebaño de la Región de Magallanes y la Antártica Chilena; las muestras de vicuñas se obtuvieron de animales mantenidos en semicautiverio en tres localidades de la Región de Arica y Parinacota. Antes de realizar la prueba serológica los sueros se sometieron a $56{ }^{\circ} \mathrm{C}$ por 30 minutos, se trataron con caolín al $25 \%$ y se adsorbieron con eritrocitos de cobayo, con el fin de eliminar las proteínas termolábiles del complemento, los inhibidores inespecíficos de la hemoaglutinación y remover posibles autohemoaglutininas (Chanock y Johnson 1964).

\section{PRUEBA DE INHIBICIÓN DE LA HEMOAGLUTINACIÓN (IHA)}

Se seleccionó esta prueba en virtud de que es la frecuentemente empleada para detectar anticuerpos contra el VPI-3. El antígeno viral consistió en VPI-3 aislado de bovino, previamente propagado en cultivos celulares de pulmón fetal bovino y titulado por prueba de hemoaglutinación (Chanock y Johnson 1964). La prueba se realizó en microplacas de 96 pocillos, para lo cual se hicieron diluciones en base 2 desde 1:8 hasta 1:256 en solución tampón fosfato salino (PBS 0,01 M pH 7,2) en volúmenes de $50 \mu \mathrm{l}$. Cada dilución de suero se mezcló, en igual volumen, con una dilución de virus que contiene ocho unidades hemoaglutinantes (UHA). Luego de incubar a $25{ }^{\circ} \mathrm{C}$ durante 60 minutos, se agregaron eritrocitos de cobayo lavados y suspendidos al $1 \%$ en PBS. En forma paralela, se realizaron controles de suero, de eritrocitos y de UHA del virus. Después de una segunda incubación por 40 minutos, se realizó la lectura de la prueba que consistió en determinar la dilución del suero con capacidad de inhibir la acción de cuatro UHA del virus (Chanock y Johnson 1964). Se consideraron como muestras positivas aquellas en que diluciones iguales o mayores a ocho tuvieron la capacidad de inhibir las cuatro UHA del virus y se interpretó como evidencia de infección con un VPI-3.

\section{RESULTADOS Y DISCUSIÓN}

En el cuadro 1 se muestra que de las 370 muestras de sueros de CSA, 91 (24,6\%) presentaron anticuerpos inhibidores de la hemoaglutinación (AcIHA) para el VPI-3 con valores entre ocho y 256 , con una media geométrica de 31 positivos. La especie que presentó mayor número de reaccionantes positivos correspondió a las llamas, con un $40,9 \%$, y el menor número de reaccionantes positivos se obtuvo en los guanacos con un 11,2\%. La razón de esto podría deberse a diferencias en la susceptibilidad de infección entre las dos especies y a las posibilidades de contacto con animales infectados tratándose de una especie doméstica, la llama, y de una especie silvestre, el guanaco, a pesar de encontrarse, esta última, en cautiverio.

En el cuadro 2 se muestra la distribución geográfica de los animales con anticuerpos para el VPI-3. En él se observa que los cuatro rebaños de alpacas y los cuatro rebaños de llamas ubicados en la Región Metropolitana tienen a lo menos un animal con anticuerpos anti-VPI-3. De igual forma, ocho de los 10 rebaños de llamas de la Región de Arica y Parinacota y los tres rebaños de vicuñas fueron reaccionantes al VPI-3. Estos antecedentes permiten establecer que el virus está presente en la población de CSA de Chile y considerar, de mayor importancia, su presencia en las regiones que concentran el $90 \%$ de la población de alpacas, llamas y vicuñas del país. Al respecto, Martín (2010) señala que una de las principales limitaciones en la producción de CSA es la elevada mortalidad de las crías, debido al manejo inadecuado y a las enfermedades infecciosas produciendo pérdidas que superan el $50 \%$ de los animales nacidos, lo que origina la pérdida de unidades productivas tanto para el autoconsumo como para la comercialización. Bajo este concepto, el VPI-3 podría tener una activa participación y su control, mediante medidas profilácticas como son el manejo adecuado de las crías, la disminución de las condiciones de estrés y el eventual empleo de vacunas, contribuiría a reducir las pérdidas productivas, lo que redunda en una mejora de las condiciones de vida de las comunidades andinas.

Cuadro 1. Distribución de títulos de anticuerpos antivirus parainfluenza 3 en camélidos sudamericanos de Chile.

Distribution of parainfluenza 3 antibody titers among Chilean South American camelids.

\begin{tabular}{|c|c|c|c|c|c|c|c|c|c|c|c|}
\hline \multirow{2}{*}{ Especie } & \multirow{2}{*}{ Muestras } & \multicolumn{7}{|c|}{ Título anticuerpos* } & \multicolumn{3}{|c|}{ Positivos** } \\
\hline & & $<8$ & 8 & 16 & 32 & 64 & 128 & 256 & $\mathrm{MG}^{* * *}$ & Total (n) & $(\%)$ \\
\hline Alpacas & 87 & 69 & 7 & 7 & 1 & 1 & 1 & 1 & 18 & 18 & 20,7 \\
\hline Llamas & 88 & 52 & 15 & 6 & 2 & 2 & 0 & 11 & 32 & 36 & 40,9 \\
\hline Guanacos & 89 & 79 & 3 & 0 & 4 & 2 & 0 & 1 & 32 & 10 & 11,2 \\
\hline Vicuñas & 106 & 79 & 6 & 5 & 3 & 5 & 2 & 6 & 42 & 27 & 25,5 \\
\hline Total & 370 & 279 & 31 & 18 & 10 & 10 & 3 & 19 & 31 & 91 & 24,6 \\
\hline
\end{tabular}

* Recíproco de la dilución de suero que inhibe cuatro unidades hemoaglutinantes de virus parainfluenza 3.

** Títulos mayores o iguales a ocho se consideran positivos.

**** Media geométrica. 
Cuadro 2. Frecuencia de camélidos sudamericanos en rebaños de diferentes lugares geográficos de Chile serológicamente reaccionantes y no reaccionantes al virus parainfluenza 3 .

Frequency of parainfluenza- 3 sero-positive and sero-negative animals from South American camelid herds from various geographical locations of Chile.

\begin{tabular}{|c|c|c|c|c|}
\hline Rebaños & Región & Positivos & Negativos & Total \\
\hline Alpacas 1 & Metropolitana & 13 & 41 & 54 \\
\hline Alpacas 2 & & 1 & 14 & 15 \\
\hline Alpacas 3 & & 2 & 10 & 12 \\
\hline Alpacas 4 & & 2 & 4 & 6 \\
\hline Llamas 1 & & 9 & 9 & 18 \\
\hline Llamas 2 & & 1 & 14 & 15 \\
\hline Llamas 3 & & 3 & 5 & 8 \\
\hline Llamas 4 & & 1 & 1 & 2 \\
\hline Llamas 5 & de Arica* & 3 & 5 & 8 \\
\hline Llamas 6 & & 4 & 4 & 8 \\
\hline Llamas 7 & & 5 & 0 & 5 \\
\hline Llamas 8 & & 0 & 5 & 5 \\
\hline Llamas 9 & & 0 & 4 & 4 \\
\hline Llamas 10 & & 3 & 1 & 4 \\
\hline Llamas 11 & & 2 & 2 & 4 \\
\hline Llamas 12 & & 3 & 1 & 4 \\
\hline Llamas 13 & & 1 & 1 & 2 \\
\hline Llamas 14 & & 1 & 0 & 1 \\
\hline Guanacos 1 & Metropolitana & 10 & 67 & 77 \\
\hline Guanacos 2 & de Magallanes** & 0 & 12 & 12 \\
\hline Vicuñas 1 & de Arica* & 16 & 30 & 46 \\
\hline Vicuñas 2 & & 10 & 34 & 44 \\
\hline Vicuñas 3 & & 1 & 15 & 16 \\
\hline
\end{tabular}

* Región de Arica y Parinacota.

** Región de Magallanes y Antártica Chilena.

\section{RESUMEN}

En un total de 370 sueros obtenidos de 87 alpacas (Lama pacos), 88 llamas (Llama glama), 89 guanacos (Lama guanicoe) y 106 vicuñas (Vicugna vicugna) se investigó la presencia de anticuerpos para el virus parainfluenza 3 (VPI-3). La prueba de inhibición de la hemoaglutinación mostró que 91 (24,6\%) de los camélidos sudamericanos (CSA) distribuidos en $18(20,7 \%)$ alpacas, $36(40,9 \%)$ llamas, $27(18,9 \%)$ vicuñas y 10 $(11,2 \%)$ guanacos tenían anticuerpos. El rango de los títulos de las muestras positivas estuvo entre 8 y 256 con una media geométrica de 31. Los resultados establecen que los CSA en Chile están infectados con VPI-3.

\section{AGRADECIMIENTOS}

A la Corporación Nacional Forestal Chile y a la Planta Faenadora de Carnes de Arica, por la cooperación en la toma de muestras.

\section{REFERENCIAS}

Berríos P, MO Celedón, A Pinto d'Aguiar, G González. 1983. Parainfluenza-3: Estudio serológico en bovinos de la zona sur de Chile (VIII, IX y X Regiones). Arch Med Vet 15, 73-79.

Berríos P, MO Celedón, M Duchens, L Lorca. 1985. Aislamiento del virus parainfluenza - 3 de bovinos con sintomatología respiratoria. Monografías Medicina Veterinaria 7, 61-62.

Berríos P, P Pérez, MO Celedón, R Zúñiga. 1987. Parainfluenza-3: Estudio serológico en ovinos de la zona central de Chile (V y VI Regiones). Arch Med Vet 19, 7-11.

Berríos P, C González, J Enciso, M Santibáñez. 1991. Aislamiento del virus parainfluenza tipo 3 en ovinos con neumonía. Av Cs Vet 6, 185-186.

Celedón MO, A Sandoval, J Droguett, R Calfío, L Ascencio, J Pizarro, C Navarro. 2001. Pesquisa de anticuerpos seroneutralizantes para pestivirus y herpesvirus en ovinos, caprinos y camélidos sudamericanos de Chile. Arch Med Vet 19, 7-11.

Celedón MO, J Osorio, J Pizarro. 2006. Aislamiento e identificación de pestivirus obtenidos de alpacas (Lama pacos) y llamas (Lama glama) de la Región Metropolitana, Chile. Arch Med Vet 38, 247-252.

Chanock RM, KM Johnson. 1964. Parainfluenza viruses. In: Lennete EH, Schmidt NJ (eds). Diagnostic Procedures for Viral and Rickettsial Diseases. $3^{\text {rd }}$ ed. American Public Health Association, INC. Broadway, New York, USA, Pp 470-486.

FIA, Fondo Innovación Agraria. 2000. Proyecto Camélidos en Chile: Situación Actual y Perspectivas. FIA, Ministerio de Agricultura, Santiago, Chile.

Martín C, CE Pinto, MD Cid. 2010. Camélidos sudamericanos: Estado sanitario de sus crías. Revista Complutense de Ciencias Veterinarias 4, 37-50.

Murphy F, E Gibbs, M Horzinek, MJ Studdert. 1999. Paramyxoviridae. In: Murphy F, Gibbs E, Horzinek M, Studdert MJ (eds). Veterinary Virology. $3^{\mathrm{a}}$ ed. Academic Press, California, USA, Pp 411-428.

Reinhardt G, M Polette, M Cano. 1980. Prospección serológica del virus parainfluenza-3 en bovinos de la provincia de Valdivia. Zbl Vet Med B 27, 144-148.

Riedemann S, N Tadich, G Reinhardt, M Montecinos, M Aguilar. 1991. Pesquisa serológica de PI-3, BHV-1 y BVDV en ovinos de 11 predios de la X Región, Chile. Arch Med Vet 23, 185-187.

Vergara F. 2004. Primera detección en Chile de anticuerpos seroneutralizantes contra herpesvirus equino tipo 1 en camélidos sudamericanos. Memoria de título, Escuela de Ciencias Veterinarias, Universidad de Chile, Santiago, Chile. 